\title{
CULTIVO DA MACADÂMIA NO BRASIL ${ }^{1}$
}

\author{
PEDRO LUÍS BLASI DE TOLEDO PIZA ${ }^{2,3}$ \& LEONARDO MASSAHARU MORIYA 4,5
}

RESUMO- Nativa da Austrália, a macadâmia foi introduzida no Brasil em 1935; entretanto, os primeiros plantios comerciais somente apareceram no final dos anos setenta. Hoje, o Brasil possui 6.500 hectares plantados com a espécie $M$. integrifolia distribuídos em 7 estados. O parque de processamento é formado por três unidades de médio porte que, juntas, beneficiam $79 \%$ da safra brasileira e vinte de pequeno porte. Em 2012, o País produziu 1.100 toneladas de amêndoas de macadâmia, 62,5\% para exportação e 37,5\% para o mercado interno. Ainda desconhecida pela maioria das pessoas, o consumo vem crescendo na mesma velocidade do aumento da produção mundial. A inclusão de alimentos saudáveis na dieta alimentar tem atraído cada vez mais consumidores para o mercado das nozes. Este fato permite afirmar que a macadâmia é um dos alimentos do futuro.

Termos para indexação: noz-macadâmia, produção, alimento saudável.

\section{MACADAMIA IN BRAZIL}

ABSTRACT-Native from Australia the macadamia nut was introduced in Brazil in 1935; however, the first commercial orchard only appeared at the end of the seventies. Now Brazil has 6.500 hectares of Macadamia integrifolia species distributed in 7 states. The processing park is formed by three midsize units, which together produce $79 \%$ of Brazilian harvest, and twenty small units. In 2012 the country produced 1,100 tons of macadamia kernel, $62.5 \%$ for export and $37,5 \%$ for internal market. Still unknown by the majority of people the macadamia consumption has been growing at the same rate of world production. The inclusion of healthy foods in the diet has attracted more and more consumers to the nut market, this fact allows to say that macadamia nut is one of the future foods.

Index terms: macadamia nut, production, healthy food

\section{INTRODUÇÃO}

A noz-macadâmia é uma planta originária da Austrália Oriental, precisamente das províncias de New South Wales e de Queensland, onde era encontrada em densas florestas naturais. Descoberta e botanicamente catalogada entre 1840 e 1860 , seu grande potencial econômico foi ignorado no país de origem por muito tempo. Introduzida no Havaí em 1881, em poucos anos, o arquipélago tornou-se um grande produtor da noz, e campanhas publicitárias incentivavam os turistas a adquirir a macadâmia que recebeu o apelido de "Noz-do-Havaí". Investimentos em controle de pragas, pesquisas varietais, tecnolo- gia de beneficiamento e comercialização colocaram a região na posição de maior produtor mundial de noz-macadâmia por quase um século. Com o início da produção mundial e o sucesso do produto, os australianos realizaram os primeiros plantios comerciais a partir de 1940 e, em produção crescente, retomaram o título de maior produtor mundial no ano 2000. A partir da divulgação das qualidades intrínsecas desta extraordinária noz, do aumento de procura por sua amêndoa e pelos seus derivados e da boa rentabilidade, diversos países plantaram macadâmia, entre os quais, os principais são África do Sul, Quênia, Guatemala, Brasil, Malauí, Colômbia e, mais recentemente, a China (Quadro 1).

${ }^{1}$ (Trabalho 444-13). Recebido em: 20-09-2013. Aceito para publicação em: 15-12-2013. Palestra II Simpósio Internacional de Fruticultura- Frutas Exóticas, 21 a 25 de outubro de 2013. Jaboticabal-SP.

${ }^{2}$ Diretor da ABM - Associação Brasileira de Noz-Macadâmia - E-mail: abm@abm.agr.br;

${ }^{3}$ Diretor da QueenNut Macadamia - E-mail: pedro@queennutmacadamia.com.br

${ }^{4}$ Conselheiro Técnico da ABM - Associação Brasileira de Noz-Macadâmia - E-mail: abm@abm.agr.br

${ }^{5}$ Gerente Agrícola da QueenNut Macadamia - E-mail: leonardo@queennutmacadamia.com.br 
Quadro 1- Área plantada com noz-macadâmia no mundo - 2012.

\begin{tabular}{|l|c|c|}
\hline \multicolumn{1}{|c|}{ PAÍS } & ÁREA (ha) & \% \\
\hline África do Sul & 19.000 & $19 \%$ \\
\hline Austrália & 17.500 & $18 \%$ \\
\hline China & 16.500 & $17 \%$ \\
\hline Quênia & 12.000 & $12 \%$ \\
\hline Guatemala & 9.000 & $9 \%$ \\
\hline Havaí (EUA) & 6.800 & $7 \%$ \\
\hline Brasil & 6.500 & $7 \%$ \\
\hline Malauí & 5.300 & $5 \%$ \\
\hline Colômbia & 1.500 & $2 \%$ \\
\hline Zimbábue & 1.500 & $2 \%$ \\
\hline Moçambique & 1.000 & $1 \%$ \\
\hline Bolívia & 1.000 & $1 \%$ \\
\hline Equador & 500 & $1 \%$ \\
\hline Paraguai & 500 & $1 \%$ \\
\hline Outros & 1.400 & $1 \%$ \\
\hline \multicolumn{1}{|c|}{ TOTAL } & $\mathbf{1 0 0 . 0 0 0}$ & $\mathbf{1 0 0 \%}$ \\
\hline
\end{tabular}

Fonte: Anais $6^{\circ}$ Simpósio Internacional de Macadâmia, 2012.

Contando com uma área plantada de 100.000 hectares no mundo, a grande maioria dos plantios ainda são jovens e não atingiram sua plenitude produtiva, fato que sinaliza um aumento de produção gradativo e consistente nos próximos anos. Atualmente, a macadâmia representa apenas $1 \%$ da produção mundial de nozes de árvore (Quadro 2).

Quadro 2- Estimativa da produção mundial de nozes de árvore -2012

\begin{tabular}{|l|c|r|c|}
\hline \multicolumn{1}{|c|}{ NOZ } & FORMA & TONELADAS & \% \\
\hline Amêndoa (Almond) & amêndoa & 1.060 .991 & $31 \%$ \\
\hline Pistáchios & em casca & 615.400 & $18 \%$ \\
\hline Castanha de Caju & amêndoa & 543.192 & $16 \%$ \\
\hline Noz de Natal (Walnut) & amêndoa & 508.137 & $15 \%$ \\
\hline Avelã (Hazelnuts) & amêndoa & 474.947 & $14 \%$ \\
\hline Noz-Pecã & amêndoa & 103.320 & $3 \%$ \\
\hline $\begin{array}{l}\text { Castanha-do-Brasil } \\
\text { C.- do-Pará) }\end{array}$ & amêndoa & 46.155 & $1 \%$ \\
\hline Macadâmia & amêndoa & 42.150 & $1 \%$ \\
\hline Pinholes (Pine nut) & amêndoa & 18.505 & $1 \%$ \\
\hline \multicolumn{2}{|c|}{ TOTAL } & $\mathbf{3 . 4 1 2 . 7 9 7}$ & $\mathbf{1 0 0 \%}$ \\
\hline
\end{tabular}

Fonte: INC, 2013.

Investimento de longo prazo, a macadâmia produz seus primeiros frutos 4 anos após o plantio e atinge sua maturidade produtiva com 12 anos, fato já constatado no Brasil. Quanto a sua longevidade, sabe-se que, no Havaí, existem pomares com até 60 anos em plena produção comercial. Desta forma, pode-se construir esquematicamente um gráfico, como o da Figura 1, que mostra a produção de uma nogueira-macadâmia ao longo de sua vida (Toledo Piza, 2000).

É comum verificar disparidades nas estatísticas de produção e de comercialização da macadamia, isto ocorre por uma característica específica deste produto. Difícil de ser quebrada ou aberta de forma doméstica, o consumidor final, sempre que possível, opta por comprar as amêndoas ao invés da noz em casca. Entretanto, beneficiadoras do mundo inteiro adotam como padrão a compra da noz em casca do produtor, criando assim uma certa confusão nas informações sobre a produção mundial. Para explicar melhor e definir com clareza as análises de rendimento e os dados de produção e consumo, é necessário conhecer o fruto da macadâmia em detalhes.

\section{Caracterização do fruto da noz-macadâmia}

Segundo Toledo Piza (2005), o fruto da macadâmia possui uma amêndoa de cor creme na parte interna, envolvida por uma casca de coloração marrom. Amêndoa e casca formam o conjunto chamado de "noz". Esta, por sua vez, quando envolvida pelo carpelo, casca de cor verde que protege a noz, constitui o que se chama de "fruto", como ilustrado nas Figuras 2 e 3.

\section{Glossário da cultura da macadâmia:}

FRUTO $=$ amêndoa + casca + carpelo. Quando maduros, os frutos caem naturalmente das árvores, e neste momento os frutos têm um teor de umidade aproximado de $25 \%$ b.s. (base seca). Após a colheita, os frutos seguem para uma unidade de pós-colheita para remoção do carpelo, seleção e armazenamento das nozes em casca. Este é um dos momentos mais críticos para a qualidade do produto, pois o alto teor de umidade acelera a germinação e quando não manuseado corretamente eleva consideravelmente a porcentagem de amêndoas mofadas, trazendo perdas elevadas ao produtor. $\mathrm{O}$ carpelo deve ser compostado e retornar na forma de adubo orgânico para o pomar.

NOZ EM CASCA = amêndoa + casca. A noz em casca ou nut-in-shell (NIS como é conhecida entre os produtores), produzida e armazenada na propriedade, é vendida nesta forma para os beneficiadores e, como referência internacional e padronização para efeito comparativo, tem seu peso ajustado para o teor de umidade de $10 \%$ b.s. 
AMÊNDOA: Parte comestível do fruto, retirada após a secagem e a quebra da noz em casca, este processo é realizado pelas beneficiadoras, e, neste momento, as amêndoas (kernel em inglês) apresentam teor de umidade de $1,5 \%$ b.s.

RENDIMENTO DE AMÊNDOAS: O rendimento de amêndoas varia consideravelmente de acordo com a variedade, região e, principalmente, com os tratos culturais. Atualmente, países com institutos de pesquisas e universidades engajados e associações de produtores organizadas são aqueles que apresentam os melhores resultados. A análise de rendimento de amêndoas boas ou a Taxa de Recuperação (TR), além de ser a base do pagamento ao produtor rural (quanto maior a TR maior o valor do lote), é um indicador da eficácia dos controles de pragas e doenças e dos procedimentos de colheita e pós-colheita do país produtor.

TAXA DE RECUPERAÇÃO - TR\%: A TR é a porcentagem de amêndoas perfeitas para consumo a partir da quebra e da seleção de cascas, amêndoas boas e amêndoas com defeitos de uma amostra. Um equívoco comum é a ideia de que somente amêndoas inteiras são boas. Nesta análise, todos os pedaços ou frações de amêndoas devem ser classificados para uma correta avaliação do lote. Para efeito de retorno ao produtor, as análises de rendimento são ainda divididas em Taxa de Recuperação Real - TR, e Taxa de Recuperação Potencial - TRp, e a diferença entre elas é, basicamente, entre o rendimento real do produto e de quanto poderia ser este rendimento se todas as práticas agrícolas e o clima conseguissem ser otimizados.

Um exemplo destas avaliações de rendimento por país e as perdas obtidas podem ser vistos no Quadro 3.

Quadro 3- Tabela de rendimento de amêndoas SAFRA 2012.

\begin{tabular}{|l|c|c|c|}
\hline \multicolumn{1}{|c|}{ PAÍS } & TR \% & TRp \% & PERDAS \% \\
\hline AUSTRÁLIA & $31 \%$ & $34 \%$ & $3 \%$ \\
\hline ÁFRICA DO SUL & $28 \%$ & $32 \%$ & $4 \%$ \\
\hline HAVAÍ & $25 \%$ & $30 \%$ & $5 \%$ \\
\hline BRASIL & $24 \%$ & $30 \%$ & $6 \%$ \\
\hline PARAGUAI & $19 \%$ & $26 \%$ & $7 \%$ \\
\hline COLÔMBIA & $18 \%$ & $26 \%$ & $8 \%$ \\
\hline
\end{tabular}

Fonte: Anais $6^{\text {th }}$ Simpósio Internacional de Macadâmia, 2012.

Considerando o rendimento e as especificidades de cada país, o Quadro 4 apresenta os dados da produção mundial de macadâmia em 2012.
Quadro 4- Produção Mundial de Noz-Macadâmia $-2012$.

\begin{tabular}{|l|c|c|}
\hline \multicolumn{1}{|c|}{ PAÍ́S } & $\begin{array}{c}\text { TONELADAS } \\
\text { AMÊNDOAS }\end{array}$ & $\begin{array}{c}\text { PARTICIPAÇÄO } \\
\text { NO } \\
\text { MERCADO }\end{array}$ \\
\hline AUSTRÁLIA & 12.500 & $30 \%$ \\
\hline ÁFRICADO SUL & 12.000 & $28 \%$ \\
\hline HAVAÍ & 6.500 & $15 \%$ \\
\hline QUÊNIA & 4.800 & $11 \%$ \\
\hline GUATEMALA & 1.900 & $5 \%$ \\
\hline MALAUÍ & 1.300 & $3 \%$ \\
\hline BRASIL & 1.100 & $3 \%$ \\
\hline CHINA & 660 & $2 \%$ \\
\hline COLÔMBIA & 250 & $1 \%$ \\
\hline OUTROS & 1.140 & $3 \%$ \\
\hline \multicolumn{1}{|c|}{ TOTAL } & $\mathbf{4 2 . 1 5 0}$ & $\mathbf{1 0 0 \%}$ \\
\hline
\end{tabular}

Fonte: INC, 2013.

\section{A noz-macadâmia no Brasil}

As primeiras árvores de macadâmia plantadas no Brasil vieram da Califórnia, em 1935. Seu cultivo, porém, destinava-se basicamente a pomares domésticos. Em 1948, técnicos do Instituto Agronômico de Campinas, em São Paulo, iniciaram experimentos para a adaptabilidade de seu cultivo comercial às condições climáticas do País. Os primeiros plantios comerciais foram realizados no final da década de 70;entretanto, somente a partir dos anos 80 , e em especial na virada da década de 90, o cultivo da macadâmia tomou grande impulso. Atualmente, o País possui 6.500 hectares plantados da espécie M. integrifólia, divididos entre os Estados de São Paulo, Minas Gerais, Espírito Santo, Rio de Janeiro, Bahia e algumas regiões do norte do Paraná e Planalto do Mato Grosso do Sul (Quadro 5).

Quadro 5- Distribuição dos plantios de macadâmia no Brasil - 2013.

\begin{tabular}{|c|c|c|c|}
\hline EST & PLANTAS & $\begin{array}{c}\text { ÁREA } \\
\text { (ha) }\end{array}$ & $\%$ \\
\hline SÃO PAULC & 0 & 3.000 & $46 \%$ \\
\hline ESPÍRITO SANTO & 220. & 1.000 & $15 \%$ \\
\hline MINAS GE & & 850 & $13 \%$ \\
\hline BAHIA & & 500 & $8 \%$ \\
\hline RIO DE . & 00 & 500 & $8 \%$ \\
\hline MATO GROS & & 500 & $8 \%$ \\
\hline PARANÁ & & 150 & $2 \%$ \\
\hline TOTAL & 1.380 .000 & 6.500 & $100 \%$ \\
\hline
\end{tabular}

Fonte: ABM - Associação Brasileira de Noz-Macadâmia 


\section{A produção brasileira}

Em 2012, foram colhidos $4.200 \mathrm{t}$ de nozmacadâmia em casca, equivalente a $1.100 \mathrm{t}$ de amêndoas. O preço médio pago para o produtor foi de $\mathrm{R} \$ 3,15 / \mathrm{kg}$ em casca ou $\mathrm{R} \$ 12,0 / \mathrm{kg}$ de amêndoa. A Figura 4 apresenta a evolução da produção brasileira de macadâmia em casca de 2008 a 2012 e a estimativa para 2013.

No Brasil, existem 3 beneficiadorasexportadoras de macadâmia de médio porte que, juntas, processaram $79 \%$ da safra brasileira em 2012, e outras 20 pequenas completam o quadro da indústria brasileira (Figura 5).

\section{O mercado de noz-macadâmia}

Há alguns anos, grande parte da macadamia produzida no Brasil era exportada, porém esta tendência vem sendo revertida. Os principais motivos são o aumento da produção brasileira, a entrada de pequenas processadoras com foco no mercado interno e o lançamento de produtos com macadamia por grandes indústrias das áreas de panificação, chocolates, sorvetes e drageados. O Quadro 6 apresenta dados dos últimos anos de produção, e a Figura 6, o destino do produto.

Quadro 6- Produção e destino da macadâmia brasileira.

\begin{tabular}{|l|c|c|c|c|c|c|}
\hline $\begin{array}{l}\text { Toneladas de } \\
\text { Amêndoas / Ano }\end{array}$ & $\mathbf{2 0 0 8}$ & $\mathbf{2 0 0 9}$ & $\mathbf{2 0 1 0}$ & $\mathbf{2 0 1 1}$ & $\mathbf{2 0 1 2}$ & $\mathbf{2 0 1 3}$ \\
\hline EXPORTAÇÃO & 425 & 368 & 566 & 706 & 688 & 700 \\
\hline $\begin{array}{l}\text { MERCADO } \\
\text { INTERNO }\end{array}$ & 165 & 202 & 264 & 354 & 412 & 500 \\
\hline \multicolumn{1}{|c|}{ TOTAL } & $\mathbf{5 9 0}$ & $\mathbf{5 7 0}$ & $\mathbf{8 3 0}$ & $\mathbf{1 . 0 6 0}$ & $\mathbf{1 . 1 0 0}$ & $\mathbf{1 . 2 0 0}$ \\
\hline
\end{tabular}

De grande valor nutritivo, a macadamia pode ser utilizada ao natural na composição de pratos finos, pães, doces, chocolates, sorvetes e tortas ou, ainda, na forma de aperitivo, torrada e salgada.

Estudos e pesquisas ressaltam os benefícios de consumir nozes, como o artigo publicado na Menezes, (2013) intitulada "Por que você deve comer castanhas". Nesta reportagem, Samira Menezes (2013) a autora cita que "quem segue o be-a-bá da boa nutrição sabe que gordura nem sempre é ruim. Longe disso. Alguns tipos dela, como as que existem nas castanhas, são essenciais para a manutenção das células e para que algumas reações químicas aconteçam no corpo, como a formação de hormônios, a circulação de vitaminas e a entrada e saída dos nutrientes das células. No mesmo artigo, a médica Anna Carolina Bordoni relata que "as gorduras do bem são as do tipo insaturadas, que podem ser encontradas nas oleaginosas e também nas sementes, como de linhaça, no azeite de oliva extravirgem, no abacate e nos óleos de macadâmia e de amêndoa".

Além do consumo alimentar, seu óleo tem sido utilizado na produção de cosméticos, como xampu, sabonete e hidratante. Outras aplicações ainda podem ser utilizadas pela indústria, dadas as propriedades abrangentes da macadâmia. 


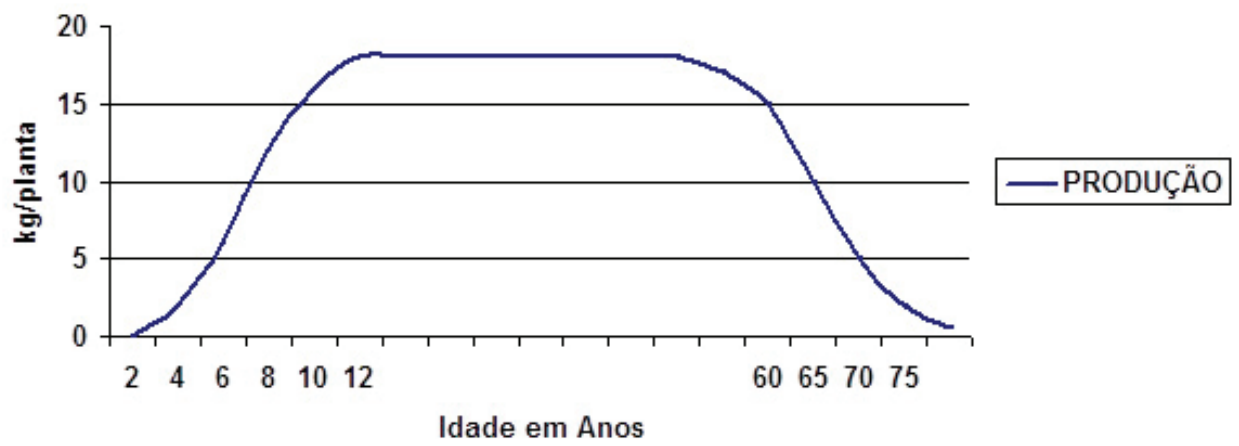

FIGURA 1- Gráfico de Produção de noz-macadâmia.

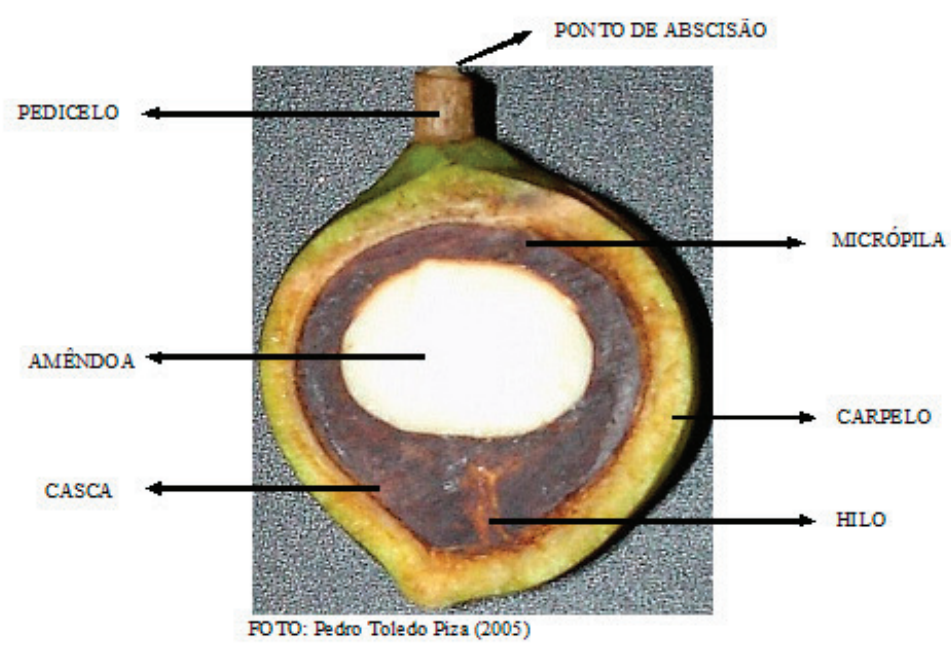

FIGURA 2- Componentes do fruto da macadâmia. FOTO: Pedro Toledo Piza (2005)

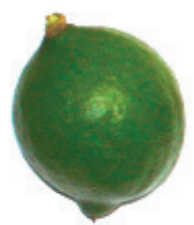

FRUTO

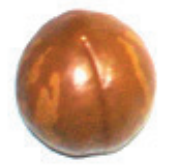

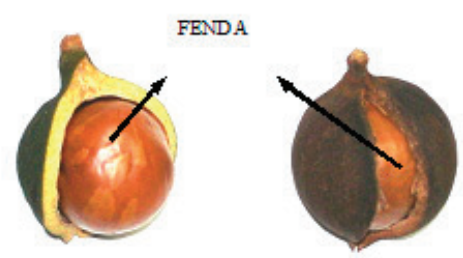

FRUTO COM FENDA NO CARPELO
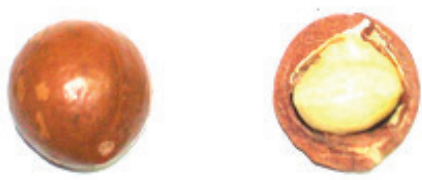

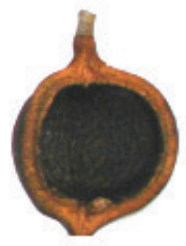

CARPELO

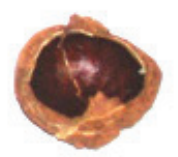

FIGURA 3- Características do fruto e da noz-macadâmia. 


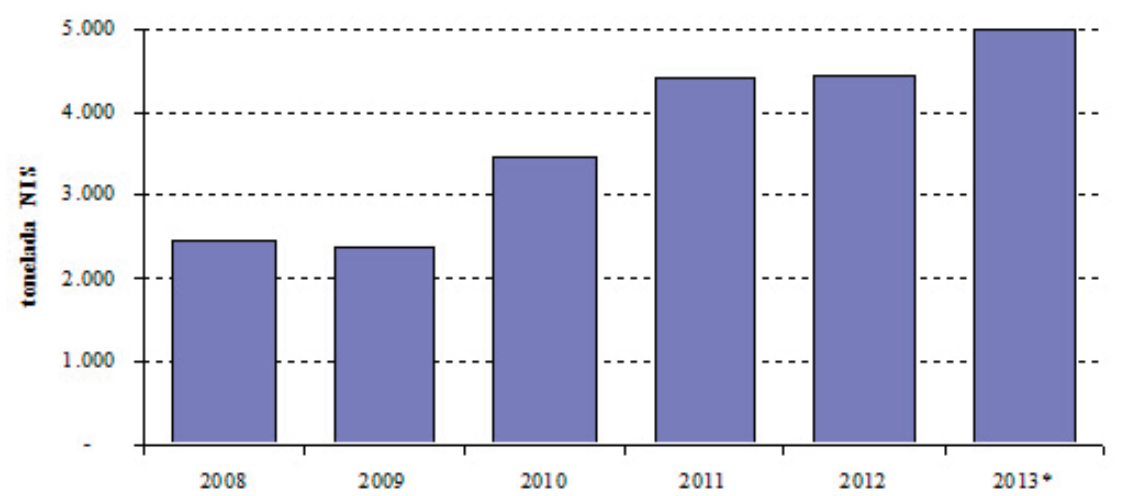

*estima do

FIGURA 4- Produção brasileira de noz-macadamia em casca (t/ano).

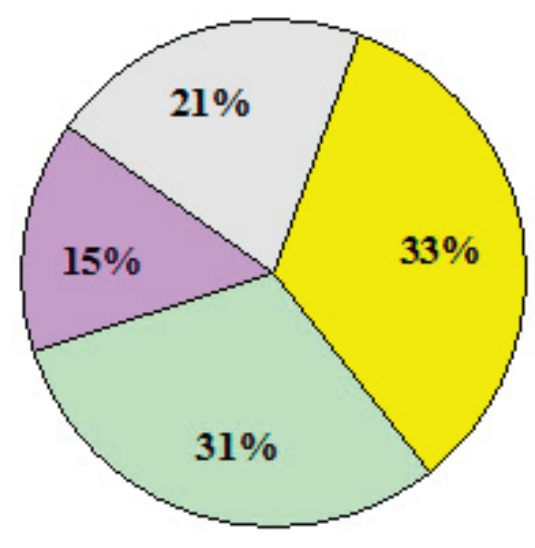

$\square$ QueenNut Mac adamia / SP

$\square$ Coopemac / ES

$\square$ Tribeca/ RJ

口Outros

FIGURA 5- Processamento de noz-macadâmia no Brasil - 2012.

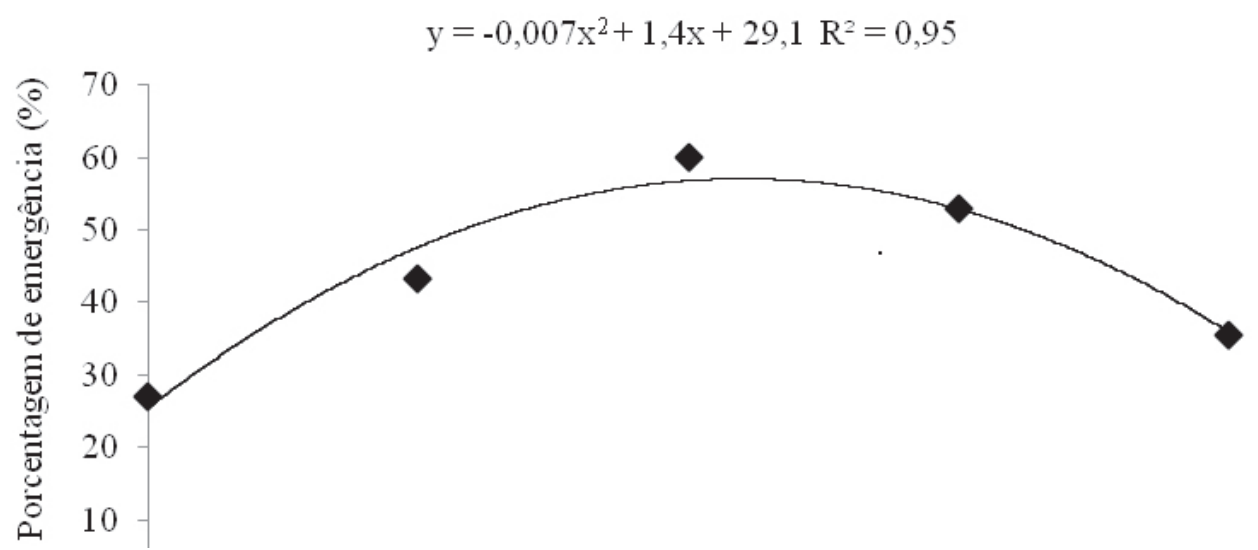

FIGURA 6- Destino da macadamia produzida no Brasil. 


\section{CONCLUSÃO}

Ainda desconhecida pela grande maioria da população o consumo de macadâmia vem crescendo no mesmo ritmo do aumento da produção mundial. Mesmo representando apenas 1\% das nozes, demanda e produção encontram-se equilibradas, exigindo pequenos esforços de divulgação e marketing para colocar o produto no mercado. Pesquisas recentes que recomendam a inclusão de nozes na dieta alimentar da população têm provocado um aumento na procura por estes alimentos criando uma legião de novos consumidores em busca de um produto saudável. Este fato permite afirmar que este é um dos alimentos, do futuro.

\section{REFERENCIAS}

ABM - Associação Brasileira de Noz Macadamia. Disponível em: <www.abm.agr.br $>$.

INC. International nut \& dried druit. 2013. Disponível em: $\leq$ https://www.nutfruit.org/en>.

INTERNATIONAL MACADAMIA SYMPOSIUM, 6., 2012, Brisbane. Proceedings... Disponível em: $\leq$ http://macadamias.org/pages/internationalsymposium-proceedings $>$.

MENEZES, S. Porque você deve comer castanhas. Revista dos Vegetarianos, São Paulo, v.7, n.78, p.16-21, 2013.
TOLEDO PIZA, P.L.B. Desempenho de unidades de pré-limpeza de frutos de macadâmia $(M$. Integrifolia). 2005. 61f. Tese (Doutorado em Agronomia) - Faculdade de Ciências Agronômicas, Universidade Estadual Paulista, Botucatu, 2005.

TOLEDO PIZA, P.L.B. Secagem e escoamento da noz macadamia (M. integrifolia) em silo secador de fundo cônico. 2000. 94 f. Dissertação (Mestrado) - Faculdade de Ciências Agronômicas, Universidade Estadual Paulista, Botucatu, 2000. 